\title{
Profissionalismo Médico e o Contrato Social: Reflexões acerca da Pandemia de COVID-19
}

\author{
Medical Professionalism and the Social Contract: \\ Reflections on the COVID-19 Pandemic
}

\author{
Maria Amélia FERREIRA ${ }^{1}$, Marco Antonio de CARVALHO FILHO ${ }^{2,3}$, Giuliani dos Santos FRANCO $\square^{4}$, \\ Renato Soleiman FRANCO 5,6 \\ Acta Med Port 2020 Jun;33(6):362-364 - https://doi.org/10.20344/amp.13769
}

\begin{abstract}
Palavras-chave: Coronavírus; COVID-19; Educação Médica; Infecções por Coronavírus; Pandemia; Profissionalismo Keywords: Coronavirus; Coronavirus Infections; COVID-19; Education, Medical; Pandemics; Professional Practice
\end{abstract}

A partir do contexto atual de saúde, numa perspetiva de mobilizações intersectoriais em diversos continentes para mitigar o avanço de uma infeção viral, perguntamos: o que podemos aprender sobre a relação entre o médico e a sociedade? Como se estabeleceu esta relação, em que se fundamenta e qual o papel do médico?

Caso para reflexão: o apoio da população aos profissionais de saúde perante a pandemia COVID-19

A população de Portugal, Brasil, Espanha, Itália, e outros países estão a manifestar apoio aos profissionais de saúde em atos que demonstram solidariedade e agradecimento. Em contrapartida, diversos profissionais através das redes sociais ou canais oficiais agradecem e atestam a importância de gestos como esses.

Estas manifestações de reconhecimento celebram o impacto positivo do trabalho dos profissionais de saúde nos lares de cada família. Neste contexto, faz-se importante salientar que o atual cenário de trabalho exige um aumento voluntário da carga horária de trabalho dos profissionais de saúde, que é necessário para responder às necessidades emergentes para enfrentar a pandemia em curso. Além do aumento das horas de trabalho, os profissionais de saúde arriscam não somente suas próprias vidas, mas também a daqueles que amam: filhos, cônjuges, pais e mães. Estes riscos são amplificados se o sistema de saúde está desorganizado, ou mal equipado, ou se faltam equipamentos de proteção individual (EPI). ${ }^{1,2}$ Por isso, nesse momento de aumento de trabalho e riscos ocupacionais, a valorização e o carinho da comunidade são essenciais para motivar e dar sentido às ações desses profissionais.

Há uma relação direta entre a dedicação dos profissionais de saúde e o apoio e reconhecimento recebidos da sociedade. As manifestações da população têm a força de um abraço forte que há tanto tempo não recebemos pelo isolamento social. D. José Tolentino Mendonça destaca que vivemos um momento de redescoberta da interdependência entre as pessoas, além de uma reaproximação a valores como o cuidado e o amor. ${ }^{3}$ A oportunidade dessa redescoberta numa relação próxima e interdependente abre as portas para aprofundarmos a discussão da relação entre a medicina e a sociedade. Ao mesmo tempo que há manifestações de solidariedade aos profissionais também é esperado que estes profissionais de saúde atuem prontamente e não se recolham, mesmo frente aos inerentes riscos. Assim, perante a cumplicidade entre os profissionais e a sociedade geral, vivificada pela pandemia COVID-19, o que podemos refletir sobre a relação entre a medicina e a sociedade?

\section{Profissionalismo médico: a relação entre medicina e a sociedade e o contrato social}

Os primeiros registos da existência de algum acordo entre o médico com a sociedade remonta ao Código de Hammurabi no Egito (entre 1728 e 1686 a.C) e ao Juramento de Hipócrates (cerca de 500 a.C). Entre os séculos XVII e XVIII, a relação entre a sociedade e suas instituições passa a ser teorizada e descrita no formato do chamado contrato social, idealizado por pensadores como Hobbes, Locke, Rousseau e Kant. Este contrato social presupõe um compromisso mútuo entre as partes envolvidas assim como direitos e deveres adquiridos (e não necessariamente conquistados). Sob as bases filosóficas congruentes com o contrato social, nos séculos XVIII e XIX a medicina é definida enquanto profissão e surgem os primeiros códigos de ética profissionais. ${ }^{4}$ No século $\mathrm{XX}$, John Rawls destaca a importância do contrato social ter um objetivo, que para ele é a justiça. Segundo Rawls, as partes envolvidas neste contrato social devem procurar mais do que o benefício próprio: devem procurar o bem-estar um do outro a partir

\footnotetext{
1. Departamento Ciências da Saúde Pública e Forenses, e Educação Médica. Faculdade de Medicina. Universidade do Porto. Porto. Portugal. Groningen. Groningen. Holanda.

3. Departamento de Medicina de Emergência. Faculdade de Ciências Médicas. Universidade de Campinas. Campinas. Brasil.

4. Departamento de Família e Comunidade da Pontifícia. Escola de Medicina. Universidade Católica do Paraná. Curitiba. Brasil.

5. Departamento de Psiquiatria da Pontifícia. Escola de Medicina. Universidade Católica do Paraná. Curitiba. Brasil.

6. Programa de Residência Médica em Psiquiatria da Prefeitura Municipal de Curitiba - FEAS/SMS. Curitiba. Brasil.

$\bowtie$ Autor correspondente: Camila Ament Giuliani dos Santos Franco. camilaament@gmail.com

Recebido: 23 de março de 2020 - Aceite: 22 de abril de 2020 | Copyright @ Ordem dos Médicos 2020
}

2. Grupo de Pesquisa LEARN (Lifelong Learning, Education \& Assessment Research Network). CEDAR - Center for Education Development and Research. Universidade de 
da imparcialidade. ${ }^{5}$

No contexto do profissionalismo médico, a ideia do contrato social tem sido utilizada como uma metáfora para a caraterização da relação entre a medicina e a sociedade. Assim, este contrato incorpora as relações e perspetivas da classe médica e da sociedade que foram construídas ao longo da história e sofreram a influência de um certo contexto cultural. Essas expetativas e relações também envolvem aquelas entre a sociedade e o estado social, como por exemplo o acesso e a qualidade dos serviços de saúde. ${ }^{6} \mathrm{O}$ contrato social não é exclusividade do médico e, de uma forma geral, diversas profissões na área da saúde compartilham a mesma essência de valores e expetativas. Assim o contrato social é amplo, mas o presente artigo foca sua discussão na relação entre a classe médica e a sociedade.

O contrato social é a base para o profissionalismo médico e engloba os direitos e deveres do médico, integrando os valores da profissão, com o objetivo de promover o bem-estar do paciente e da sociedade. ${ }^{7,8}$ Entre esses direitos e deveres, o cuidado, competência, altruísmo, integridade, responsabilidade e promoção do bem comum são as principais expetativas da sociedade em relação aos médicos. Por outro lado, confiança, autonomia, reconhecimento social, autorregulação e o financiamento de um sistema de saúde que permita um exercício adequado da profissão são as principais expetativas dos médicos face à sociedade. ${ }^{7}$ Assim, é possível concluir que há valores sólidos no contrato social que impulsionam a prática médica. No entanto, como equilibrar estes valores, deveres e expetativas em situações de crise, como a epidemia que enfrentamos neste momento?

Os riscos inerentes a situações de epidemia e pandemia levam o contrato social aos seus limites. Por exemplo, num artigo sobre a epidemia de ébola na África, Mugele e Priest fazem uma crítica à exposição aos riscos que os médicos e enfermeiros foram sujeitos e o grande número de mortes entre esses profissionais. ${ }^{2}$ Os riscos vividos na epidemia pelo vírus Ébola, agora repetem-se à escala global. Apesar da infeção por Ébola ter uma letalidade maior, a escala global da pandemia por COVID-19 faz com que a mortalidade entre os profissionais de saúde tenha uma magnitude sem precedentes. Ao mesmo tempo, os sistemas de saúde mostram-se frágeis e muitas vezes insuficientes e impreparados. ${ }^{1}$ Este risco de morrer e o possível colapso do sistema de saúde, colocam o profissional num dilema ético. Se por um lado a sociedade reconhece e glorifica o trabalho dos médicos, por outro requer que esses profissionais estejam sempre prontos, independente das condições. Por definição um dilema não tem uma resposta certa ou errada, mas precisamos de discutir se deve haver um limite para esses riscos.

Ao questionar esses limites discutem-se elementos essenciais desse contrato como, por exemplo, a responsabilidade do médico e a sua autonomia para decidir se se vai expôr ou não. Seria justo os médicos serem expostos a risco? Seria injusto com a sociedade deixar de oferecer os cuidados perante determinadas situações?

\section{O contrato social e a participação da sociedade}

Uma relação baseada não somente em regras pré-definidas (contrato), mas que incluísse uma discussão crítica entre a sociedade e os médicos poderia tornar mais claras as justiças e injustiças dos acordos entre as partes. Amartya Kumar Sen inclui e reforça a participação pública entre os sujeitos comprometidos e envolvidos num debate crítico e reflexivo na definição do que seria justo e esperado. Assim, haveria uma construção social do que seria considerado justo em relação às expetativas frente aos médicos nessa situação. ${ }^{9}$

A participação ativa da sociedade e o debate crítico são importantes para evitar que regras rígidas acabem por gerar injustiças, não só em situação de crise, mas mesmo em situações de mudança do contexto cultural ou social. No caso da epidemia por COVID-19, quer os médicos quer as sociedades estão sujeitos a sacrifícios. Enquanto os médicos arriscam as suas vidas, a sociedade abre mão da sua autonomia e muitos correm o risco de desemprego e de falta de assistência. ${ }^{1}$

Incluir a participação social e o estímulo às discussões com a sociedade pode ampliar os horizontes da relação e dos valores da profissão médica. A ampliação desses horizontes destaca uma relação de parceria, colaboração, diálogo e solidariedade; elementos essenciais para avançarmos numa construção de uma relação colaborativa entre a medicina e a sociedade. ${ }^{6}$ Assim, definir se seria justo ou não expôr os médicos a determinadas situações exigiria uma discussão crítica entre a sociedade e a medicina mais do que definir, a partir de regras, que os médicos e os demais profissionais de saúde, são responsáveis e devem agir sempre.

\section{De volta ao nosso caso para reflexão: do contrato para um modelo colaborativo}

$\mathrm{O}$ ato da população, como o de bater palmas e a atual parceria necessária aos cuidados em de saúde geram uma situação de vínculo intenso dos profissionais de saúde com a sociedade. Este vínculo facilita o debate público sobre o que é justo e sobre o que os médicos devem esperar da sociedade e vice-versa. Acreditamos ser dever do médico estar ativamente presente em momentos de crise e o contrato social promove a importância dos valores, em especial a responsabilidade e a prontidão a enfrentar a situação visando ao máximo o benefício de todos. ${ }^{10}$ No entanto, o contrato social também pode trazer regras ou expetativas inalcançáveis para a profissão médica. Podemos avançar para um modelo com maior participação social e debate do papel do médico, dos valores e expetativas em relação à medicina. Surgirão certamente, nesse modelo, novos dilemas e exigências, mas estaremos mais próximos e seremos orientados não apenas por regras e códigos como também pela nossa consciência crítica, cuidado e amor.

\section{AGRADECIMENTOS}

Agradecemos a todos os profissionais de saúde pelo incessante trabalho e a sociedade em geral pelo apoio, 
mesmo em face às perdas e às mais variadas dificuldades. Manifestamos nossos sentimentos de pesar a todas as famílias sofreram perdas inestimáveis na atual pandemia. A Mario Antonio Sanches pelo auxílio na discussão de temas densos na área da Ética e Bioética. A Victor Kenichi Morisawa e Flávia Centenaro de Oliveira pelo apoio na revisão da versão do texto em Inglês.

\section{REFERÊNCIAS}

1. Rosenbaum L. Facing covid-19 in Italy - ethics, logistics, and therapeutics on the epidemic's front line. N Engl J Med. 2020:(in press) doi:10.1056/ NEJMp2005492.

2. Mugele J, Priest C. A good death - ebola and sacrifice. N Engl J Med. 2014;371:1185-7.

3. Mendonça JT. Esperança. RevExpresso. 2020 mar 22

4. MacKenzie CR. Professionalism and medicine. HSS J. 2007;3:222-7.

5. Rawls J. Uma teoria da Justiça. $4^{\mathrm{a}}$ ed. São Paulo: Martins Fontes; 2016

6. Reid L. Medical professionalism and the social contract. Perspect Biol

\section{CONFLITOS DE INTERESSE}

Os autores declaram não haver conflitos de interesses.

\section{FONTES DE FINANCIAMENTO}

Não houve suporte financeira para este trabalho.

Med. 2011;54:455-69

7. Richard L, Cruess SR. Expectations and obligations: professionalism and medicine's social contract with society. Perspect Biol Med. 2008;51:579-98.

8. Brody H, Doukas D. Professionalism: a framework to guide medical education. Med Educ. 2014;48:980-7.

9. Sen AK. A ideia de justiça. Lisboa: Companhia das Letras; 2011

10. Malm H, May T, Francis LP, Omer SB, Salmon DA, Hood R. Ethics, pandemics, and the duty to treat. Am J Bioeth. 2008;8:4-19. 